\title{
Zinc oxide-paper based sensor for photoconductive ultraviolet detection
}

\author{
Mohammad Shafiq Che Soh, Mastura Shafinaz Zainal Abidin, Shaharin Fadzli Abd Rahman, \\ Shuthish Elangkovan, Ahmad Bukhairi Md Rashid \\ School of Electrical Engineering, Faculty of Engineering, Universiti Teknologi Malaysia, Malaysia
}

\begin{tabular}{|c|c|}
\hline Article Info & ABSTRACT \\
\hline Article history: & \multirow{13}{*}{$\begin{array}{l}\text { Paper based sensor is the new technology to fabricate a simple, portable, and } \\
\text { low cost device that exhibits the comparable properties and functions with } \\
\text { those fabricated using complex fabrication process. Paper based sensor is } \\
\text { usually applied in environmental monitoring, health diagnostics, and food } \\
\text { quality control. This research is focusing on the paper based sensor that will } \\
\text { contribute to the development of ultraviolet (UV) sensor. The fabrication of } \\
\text { the sensor was done by using different grade of pencil, namely } 6 \mathrm{~B} \text { and } 2 \mathrm{~B} \text { on } \\
\text { different type of paper. The different grade of pencil corresponds to different } \\
\text { percentage of graphite and clay. As for the type of paper, A4 printing paper } \\
\text { and Whatman filter paper were used. UV sensing operation was analyzed } \\
\text { from the measurement of current-voltage (I-V) characteristics under } \\
\text { the exposure of UV light. Zinc oxide (ZnO) was coated on the sensor to } \\
\text { facilitate the detection in the presence of UV. The sample fabricated using } \\
6 \mathrm{~B} \text { pencil grade on A4 printing paper and with ZnO coating showed a better } \\
\text { UV sensing performance compared to other samples. This is due to the high } \\
\text { conduction of 6B pencil grade and smooth surface of A4 printing paper. } \\
\text { The ZnO coating increased the sensor sensitivity and response towards } \\
\text { the UV light. These findings provide valuable information which can be used } \\
\text { in fabricating a low-cost and simple UV paper sensor. }\end{array}$} \\
\hline Received Jan 22, 2020 & \\
\hline Revised Mar 25, 2020 & \\
\hline Accepted Apr 14, 2020 & \\
\hline Keywords: & \\
\hline Graphite & \\
\hline Paper & \\
\hline Sensor & \\
\hline Ultraviolet & \\
\hline $\mathrm{ZnO}$ & \\
\hline & \\
\hline & \\
\hline & \\
\hline
\end{tabular}

Copyright $@ 2020$ Institute of Advanced Engineering and Science. All rights reserved.

\section{Corresponding Author: \\ Mastura Shafinaz Zainal Abidin, School of Electrical Engineering, Faculty of Engineering, Universiti Teknologi Malaysia, 81310 Johor Bahru, Malaysia. Email: m-shafinaz@utm.my}

\section{INTRODUCTION}

The fabrication of the ultraviolet (UV) sensors in the form of integrated circuit (IC) used a lot of electronics components such as transistors, capacitors, and resistors which made the fabrication process become challenging [1-4]. The current development of UV sensors involves complex fabrication and it is very costly because of the expensive tools and materials usage $[4,5]$. It also takes a longer time to be fabricated due to lenghthy process to undergone and risky to the environment such as causing pollution by chemical hazardous.

This study is targeted to fabricate a device or sensor that suitable and safe to the end user and the environment [6-10]. The device or sensor developed also reliable and easy to be fabricated with less pollution risk that might occur due to the fabrication process. By using environmental friendly materials [11-14] such as paper which acts as the substrate and zinc oxide $(\mathrm{ZnO})$ as a coating on the paper, the performance of the sensor for detection in the presence of the UV could be enhanced [5, 15-20].

Paper is used as the substrate due to the chemical properties of the paper that has a good porosity and higher degree of permeability. A good porosity properties can contribute to a better conductivity where 
higher porosity will induce higher conductivity $[11,20]$. The different grade of pencil which is $2 \mathrm{~B}$ and $6 \mathrm{~B}$ have different percentage of graphite and clay will be used to design sensing electrode on the paper [9, 21-23]. The design utilize the interdigitated electrode pattern that can increase the total active area for the sensing region [24]. The paper based sensor was fabricated with $\mathrm{ZnO}$ coating because it offers the properties of higher photosensitivity and larger bandgap [17]. Hence, the binding reaction between the cellulose fibers of the paper with the $\mathrm{ZnO}$ will improve the adsorption and desorption process of the sensor [15, 18, 20, 25].

\section{RESEARCH METHOD}

The development of the UV sensor in this study was started by identifying the type for graphite source and the paper. Two grades of pencil were used as the source of graphite: $2 \mathrm{~B}$ and $6 \mathrm{~B}$. As for the paper selection, two types of paper have been used: A4 printing paper and Whatman filter paper. The trace of the graphitic layer on the paper basically able to induce conductivity. The morphology of the graphitic layers in pencil and paper was observed by using Variable Pressure-Scanning Electron Microscope (JEOL JSMIT300LV VP-SEM) to determine the basic properties of the materials' morphology.

Next, the $\mathrm{ZnO}$ layer was coated on the graphite/paper structure before undergoing the evaluation on sensing characteristic. The performance of the sensor in terms of consistency and sensitivity in the presence of UV was investigated using Semiconductor Device Analyzer (Keysight B1500A). For the preparation of paper as the substrate for the sensor, selection of the paper used was done based on the thickness which is in gram per square meter (gsm) and surface roughness. The summary of thickness and surface condition for respective types of paper used for this study are shown in Table 1.

Table 1. Specification of paper substrate

\begin{tabular}{ccc}
\hline \multicolumn{1}{c}{ Paper type } & Thickness & Surface \\
\hline A4 printing paper & $80 \mathrm{gsm}$ & Smooth \\
Whatman filter paper & $80 \mathrm{gsm}$ & Rough \\
\hline
\end{tabular}

Different grade of pencil has been chosen due to the difference in the percentage composite of graphite and clay in the pencil. The grade of pencils used for this study were $2 \mathrm{~B}$ and $6 \mathrm{~B}$. The $2 \mathrm{~B}$ pencil has $74 \%$ of graphite while the $6 \mathrm{~B}$ pencil has $84 \%$ of graphite. The $6 \mathrm{~B}$ pencil grade was expected to give a better conductivity compared to $2 \mathrm{~B}$. As illustrated in Figure 1, the pattern design was drawn onto two types of paper which are A4 printing paper and filter paper using different graphite traces on the paper which is $2 \mathrm{~B}$ and $6 \mathrm{~B}$ pencil grade. The graphite traces on the paper acts as the sensing area for the detection of UV.

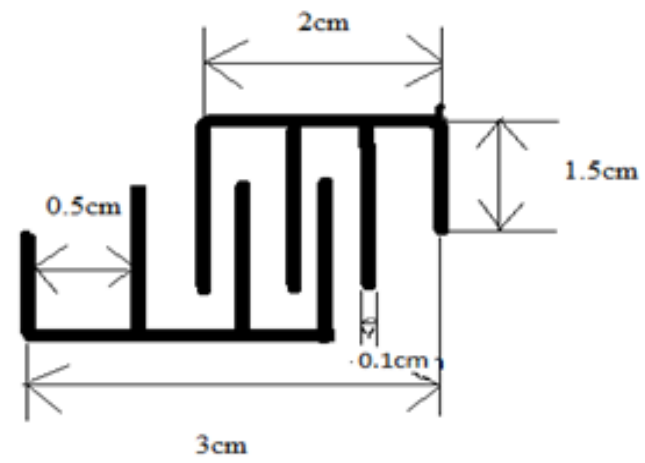

Figure 1. Pattern design of the sensor

The procedures for the preparation of graphite on paper are summarized as follows:

a. The paper was cut into several pieces of square shape for different grade of pencil with dimensions of $3 \mathrm{~cm} \times 3 \mathrm{~cm}$.

b. Different grade of pencils (2B and $6 \mathrm{~B}$ ) were used to draw the interdigitated pattern of graphitic traces on the paper that act as the sensing area.

c. The thickness of graphitic layers drawn on the paper was manually controlled by constant hand pressure in applying the same number of pattern's traces. 
To determine the morphology of the graphitic layers in pencil and paper, the samples of $2 \mathrm{~B}$ and $6 \mathrm{~B}$ pencil traces were prepared and observed under VP-SEM. In order to increase the performance of the sensor in the detection of UV, $\mathrm{ZnO}$ was coated on the sensing area. For this purpose, the $\mathrm{ZnO}$ aqueous (100nm of particle size (TEM), $\leq 40 \mathrm{~nm}$ average particle size (APS), and concentration about $20 \mathrm{wt} \%$ in $\mathrm{H}_{2} 0$.) supplied from Sigma Aldrich had been used. The $5 \mu \mathrm{L}$ of the $\mathrm{ZnO}$ aqueous was dropped on the sensing area by using micropipette and was heated using hotplate at $60^{\circ} \mathrm{C}$ for 4 minutes to remove the remaining water from $\mathrm{ZnO}$ on the paper substrates.

After the fabrication process has been completed, the measurement to determine the consistency and sensitivity of the sensor was conducted using Keysight B1500a semiconductor device analyzer. The CurrentVoltage characteristics (I-V) was measured at voltage from $-5 \mathrm{~V}$ to $5 \mathrm{~V}$. To determine the performance of the paper based sensor in the presence of light, the sample was placed in a box with dimension of $17 \mathrm{~cm} \times 17 \mathrm{~cm}$, as shown in Figure 2. The experiment to determine the effect of light on the paper based sensor were conducted under three conditions: (i) dark, (ii) LED $(\lambda=365 \mathrm{~nm})$ that act as UV source, and (iii) Laser source $(\lambda=532 \mathrm{~nm})$.

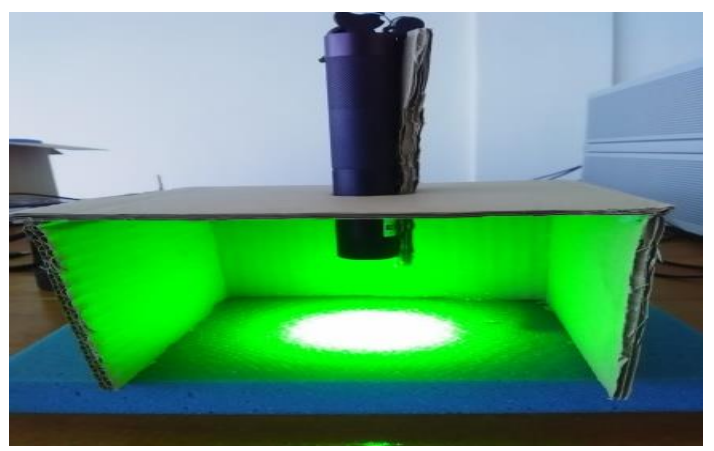

Figure 2. Measurement prototype for sample with presence of light source

\section{RESULTS AND ANALYSIS}

The morphology of the graphitic layers of different pencil grade ( $2 \mathrm{~B}$ and $6 \mathrm{~B}$ ) were observed as shown by Figures 3 and 4 respectively. Based on Figure 5, the morphology of the paper was observed as the cellulose fibers structure which is useful to hold the molecules of $\mathrm{ZnO}$ in the adsorption-desorption process and able to increase the photoconductivity [15]. The performance of paper based sensor in terms of consistency and sensitivity are mainly affected by the type of paper and graphite grade used in the experiment. The relationship of current between different type of graphite and paper were measured. For the I-V characteristics which involved $2 \mathrm{~B}$ and $6 \mathrm{~B}$ pencil with different type of paper, the consistency and sensitivity were determined by the slope of I-V characteristics. By referring to Figure 6, the lower slope had produced a higher resistance. From the analysis between $2 \mathrm{~B}$ and $6 \mathrm{~B}$ pencil grade samples, the $2 \mathrm{~B}$ had higher resistance compared to $6 \mathrm{~B}$. Hence, the higher conductivity could be achieved by $6 \mathrm{~B}$ sample.

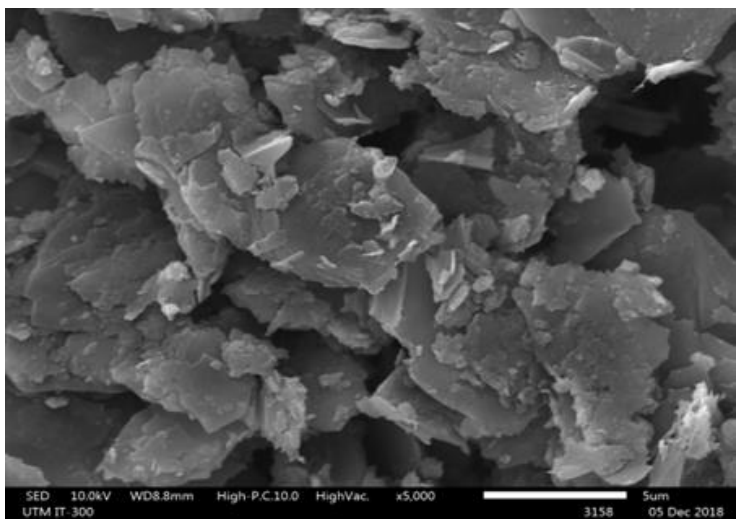

Figure 3. SEM image for graphitic layers of 2B pencil trace

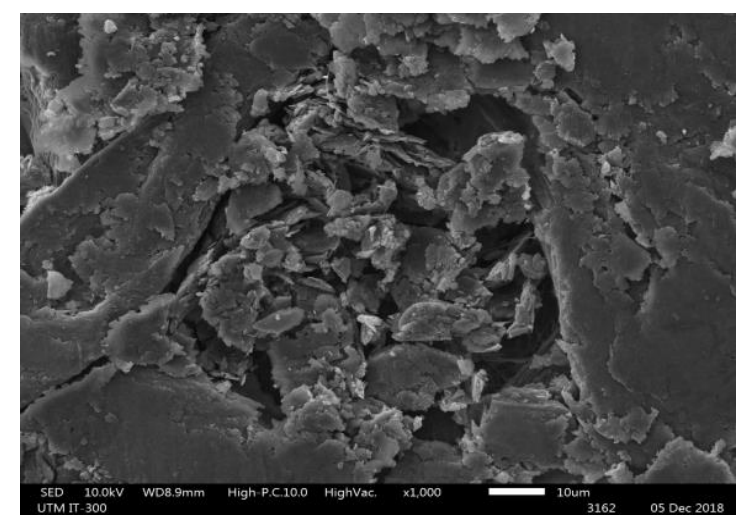

Figure 4. SEM image for graphitic layers of $6 \mathrm{~B}$ pencil trace 


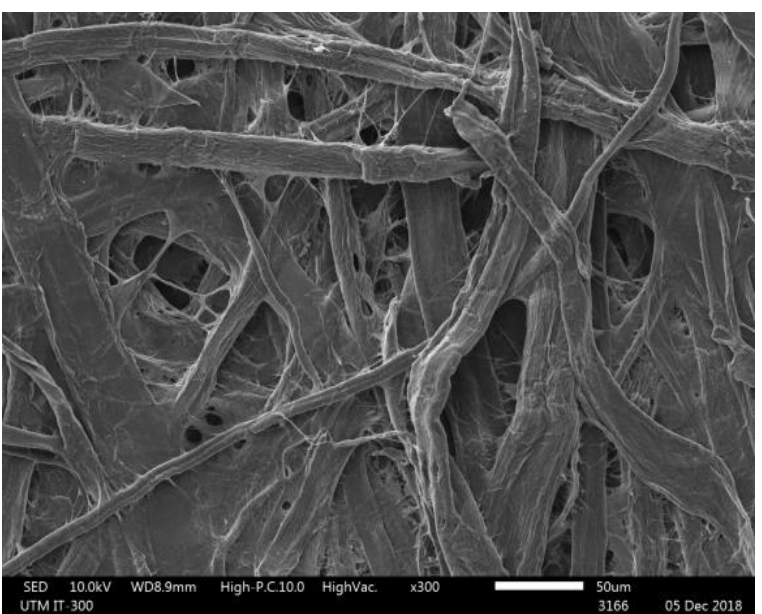

(a)

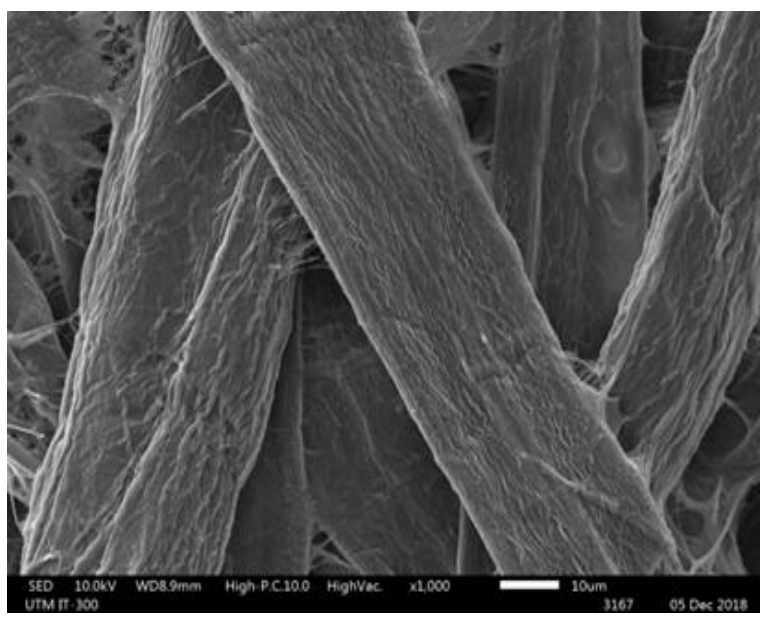

(b)

Figure 5. SEM image for morphology of filter paper at magnification of, a) 300x and b) 1000x

Surface roughness of A4 printing paper and filter paper also would affect the performance of the sensor [26]. The I-V characteristics under dark condition for both A4 printing paper and filter paper samples were compared in Figure 6. Current fluctuation was observed in filter paper sample's result. This occurrence could be due to the filter paper's properties itself where it has more rough surface area compared to the A4 printing paper. A significant ripple in response's result for both $2 \mathrm{~B}$ and $6 \mathrm{~B}$ pencil grade trace on the filter paper were obtained, which make it concluded that the sample was not suitable to be used as the sensor. In this case, the filter paper was seen as poor to act as substrate as it may deteriorate the overall performance of the sensor.

Next, the performance of the sensor was expected to be by introducing the $\mathrm{ZnO}$ coating. The presence of $\mathrm{ZnO}$ would facilitate the adsorption-desorption process between the paper and the atmospheric oxygen [15]. In the three conditions where the experiment conducted, the resistance of the sensor in dark condition was the highest. Basically, the resistance varied and decreased when it was exposed to LED source. A greater current changes was observed when the samples were exposed to Laser source that had higher wavelength compared to LED. The comparison of I-V characteristics of the samples with and without $\mathrm{ZnO}$ coating on A4 printing paper can be observed in Figure 7. It seems that combination of A4 printing paper and $6 \mathrm{~B}$ pencil grade gave a better result consistency compared to other combination and higher current response could be detected with the presence of $\mathrm{ZnO}$ coating on the samples.

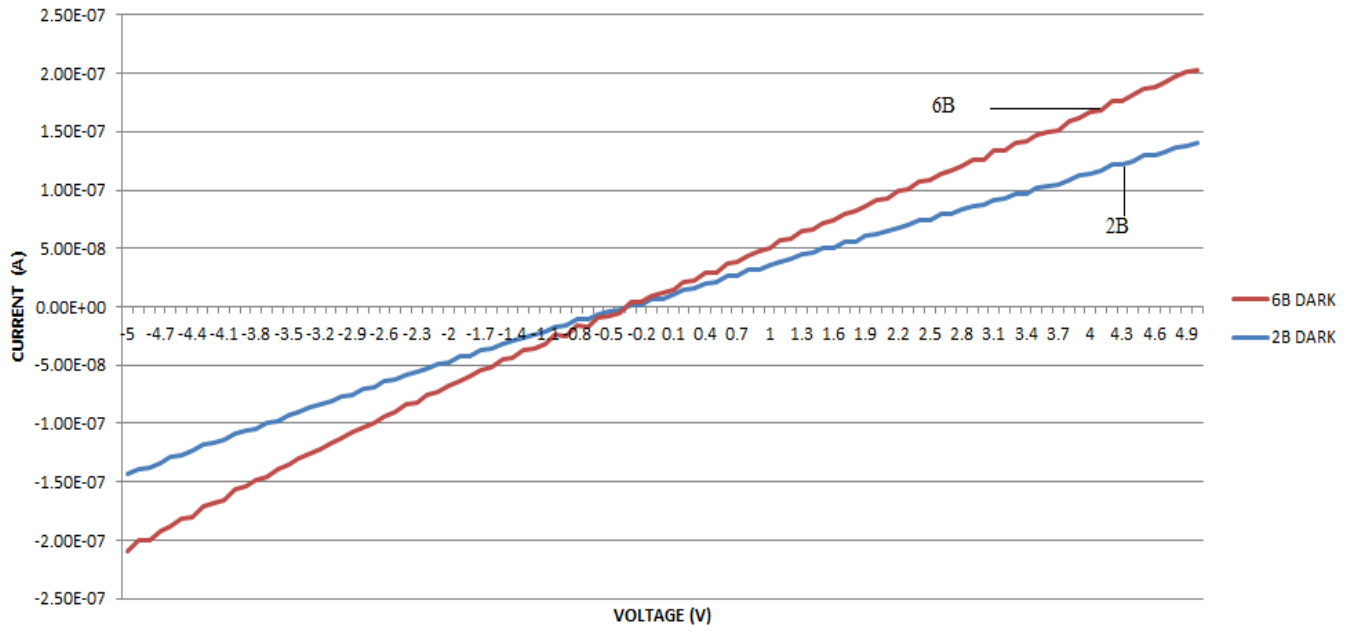

(a) A4 printing paper 


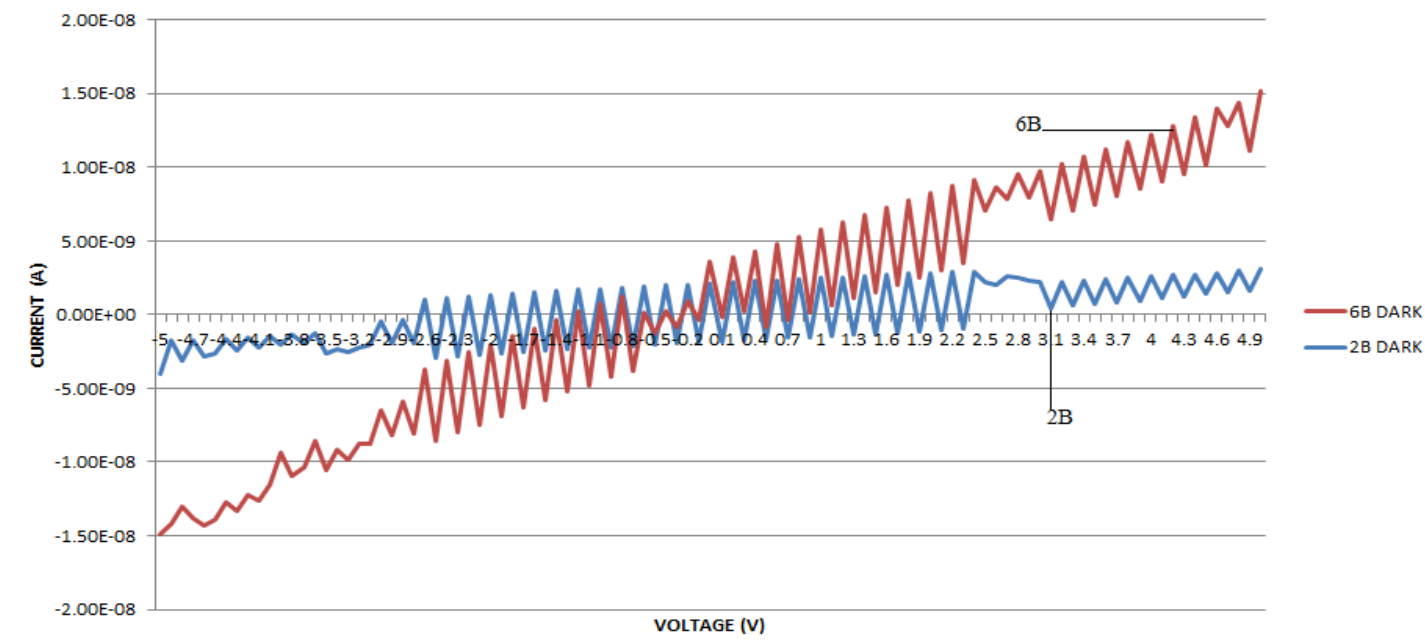

(b) filter paper

Figure 6. The I-V characteristics for $2 \mathrm{~B}$ and $6 \mathrm{~B}$ samples using

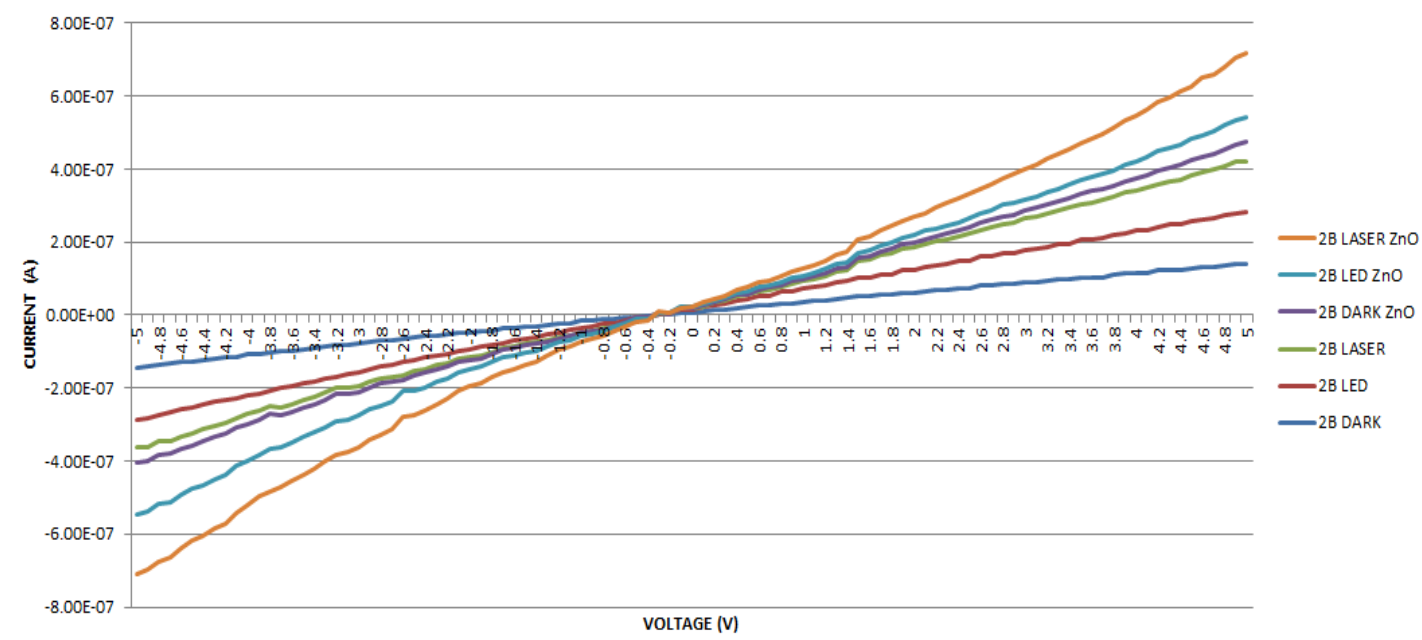

(a) $2 \mathrm{~B}$ pencil

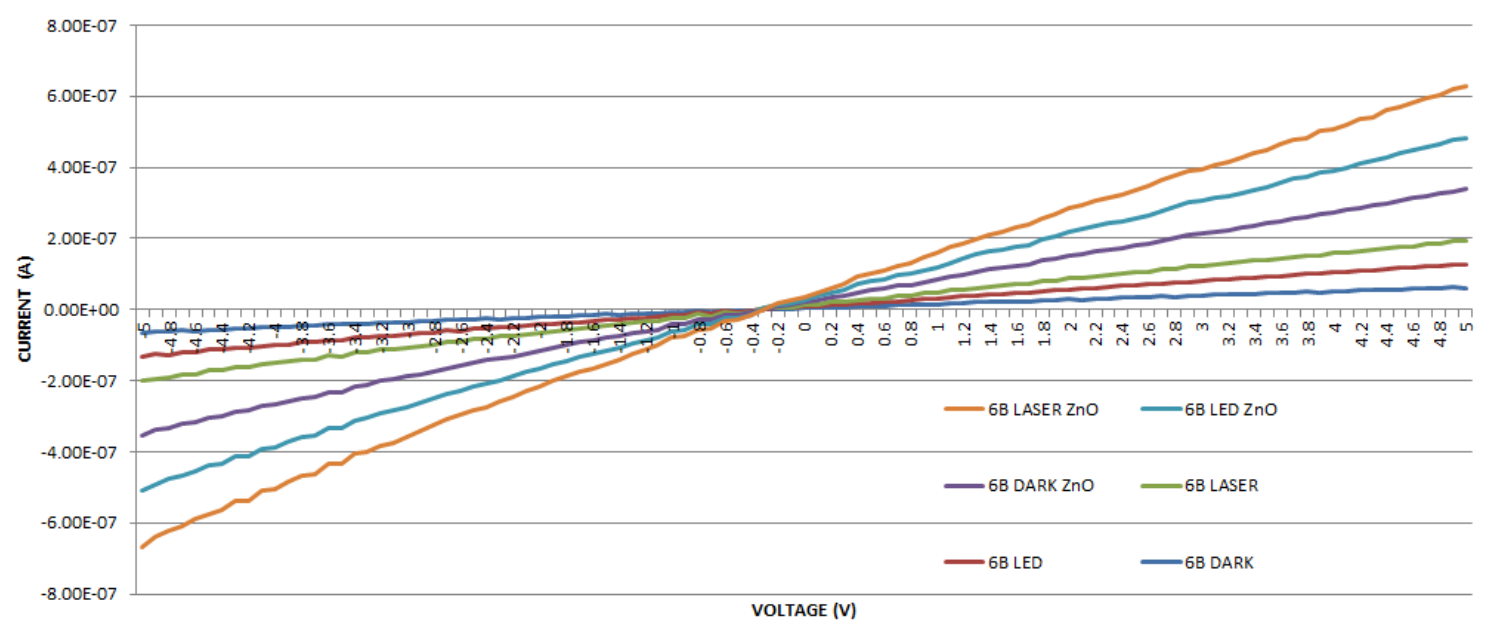

(b) $6 \mathrm{~B}$ pencil

Figure 7. The I-V characteristics of samples with and without $\mathrm{ZnO}$ coating on $\mathrm{A} 4$ printing paper using graphitic traces 


\section{CONCLUSION}

In this study, the fabrication of UV sensor by using environmental friendly materials has been implemented. The fabrication process of the sensor is easy and involves low cost of implementation. Different grade of pencil such as $2 \mathrm{~B}$ and $6 \mathrm{~B}$ has been used as the source of graphite to design the sensor. The design of the sensor used interdigitated electrode to increase the active area and sensing area. Thus, increase the conductivity of the sensor. Fabrication by using $\mathrm{ZnO}$ and paper shows a better conductivity compared to the fabrication without using $\mathrm{ZnO}$. The better conductivity occurred due to the adsorption-desorption processed that occurred at the surface of the sensor with the atmospheric $\mathrm{O}^{2}$. From the I-V characteristics and time response obtained by using Semiconductor Device Analyzer, combination of A4 printing paper and 6B pencil grade shows a better result due to the smooth surface area compared to the filter paper and also due to the percentage of graphite in the pencil.

\section{ACKNOWLEDGEMENTS}

This work has been supported by Universiti Teknologi Malaysia and Ministry of Higher Education (Grant no: R.J130000.7823.4F926, FRGS/1/2017/TK04/UTM/02/33).

\section{REFERENCES}

[1] Cheong, P., et al., "A ZigBee-Based Wireless Sensor Network Node for Ultraviolet Detection of Flame," IEEE Transactions on Industrial Electronics, vol. 58, no. 11, pp. 5271-5277, 2011.

[2] Sang, L., M. Liao, and M. Sumiya, "A Comprehensive Review of Semiconductor Ultraviolet Photodetectors: From Thin Film to One-Dimensional Nanostructures,” Sensors, vol. 13, no. 8, pp. 10482-10518, 2013.

[3] Zou, Y., et al., "Ultraviolet Detectors Based on Wide Bandgap Semiconductor Nanowire: A Review," Sensors (Basel), vol. 18, no. 7, p. 2072, 2018.

[4] Chen, H., et al., "New concept ultraviolet photodetectors," Materials Today, vol. 18, no. 9, pp. 493-502, 2015

[5] Gimenez, A. J., J. M. Yáñez-Limón, and J. M. Seminario, "ZnO-Paper Based Photoconductive UV Sensor," The Journal of Physical Chemistry C, vol. 115, no. 1, pp. 282-287, 2011.

[6] Liana, D. D., et al., "Recent Advances in Paper-Based Sensors," Sensors, vol. 12, no. 9, pp. 11505-11526, 2012.

[7] Cheng, C. -M., et al., "Paper-Based ELISA," Angewandte Chemie International Edition, vol. 49, no. 28, pp. 4771-4774, 2010.

[8] Singh, A. T., et al., "Paper-Based Sensors: Emerging Themes and Applications," Sensors, vol. 18, no. 9, p. $2838,2018$.

[9] Kurra, N. and G. U. Kulkarni, "Pencil-on-paper: electronic devices," Lab on a Chip, vol. 13, no. 15, pp. 2866-2873, 2013.

[10] Nery, E. W. and L. T. Kubota, "Sensing approaches on paper-based devices: a review," Analytical and Bioanalytical Chemistry, vol. 405, no. 24, pp. 7573-7595, 2013.

[11] Klemm, D., et al., "Cellulose: Fascinating Biopolymer and Sustainable Raw Material," Angewandte Chemie International Edition, vol. 44, no. 22, pp. 3358-3393, 2005.

[12] Barmpakos, D., et al., "A disposable flexible humidity sensor directly printed on paper for medical applications," in Journal of Physics Conference Series, vol. 931, 2017.

[13] Costa, M. N., et al., "A low cost, safe, disposable, rapid and self-sustainable paper-based platform for diagnostic testing: lab-on-paper," Nanotechnology, vol. 25, no. 9, p. 094006, 2014.

[14] Irimia-Vladu, M., “"'Green" electronics: biodegradable and biocompatible materials and devices for sustainable future," Chemical Society Reviews, vol. 43, no. 2, pp. 588-610, 2014.

[15] $\mathrm{Li}, \mathrm{Q}$. H., et al., "Adsorption and desorption of oxygen probed from $\mathrm{ZnO}$ nanowire films by photocurrent measurements," Applied Physics Letters, vol. 86, no. 12, p. 123117, 2005.

[16] Bai, S., et al., "High-Performance Integrated ZnO Nanowire UV Sensors on Rigid and Flexible Substrates," Advanced Functional Materials, vol. 21, no. 23, pp. 4464-4469, 2011.

[17] Gimenez, A. J., et al., "Paper-Based ZnO Oxygen Sensor," IEEE Sensors Journal, vol. 15, no. 2, pp. 1246-1251, 2015.

[18] Hasan, K. U., O. Nur, and M. Willander, "Screen printed ZnO ultraviolet photoconductive sensor on pencil drawn circuitry over paper," Applied Physics Letters, vol. 100, no. 21, p. 211104, 2012.

[19] Amini, E., et al., "Solution-Processed Photoconductive UV Detectors Based on ZnO Nanosheets," IEEE Photonics Technology Letters, vol. 24, no. 22, pp. 1995-1997, 2012.

[20] Gimenez, A. J., J. M. Yanez-Limon, and J. M. Seminario, "ZnO-Cellulose Composite for UV Sensing," IEEE Sensors Journal, vol. 13, no. 4, pp. 1301-1306, 2013.

[21] Kang, T.-K., "Tunable piezoresistive sensors based on pencil-on-paper," Applied Physics Letters, vol. 104, no. 7, p. 073117,2014

[22] Akanda, M. R., et al., "Recent Advances in Nanomaterial-Modified Pencil Graphite Electrodes for Electroanalysis," Electroanalysis, vol. 28, no. 3, pp. 408-424, 2016.

[23] Kariuki, J. K., "An Electrochemical and Spectroscopic Characterization of Pencil Graphite Electrodes," Journal of the Electrochemical Society, vol. 159, no. 9, pp. H747-H751, 2012.

[24] Zhang, J., et al., "Pencil-trace on printed silver interdigitated electrodes for paper-based NO2 gas sensors," Applied Physics Letters, vol. 106, no. 14, p. 143101, 2015.

[25] Niarchos, G., et al., "Paper-based Humidity Sensor Coated with ZnO Nanoparticles: The Influence of ZnO," Procedia Engineering, vol. 168, pp. 325-328, 2016.

[26] Nurzaman, S. G., et al., "Active sensing system with in situ adjustable sensor morphology," PloS one, vol. 8, no. 12, pp. e84090-e84090, 2013. 


\section{BIOGRAPHIES OF AUTHORS}
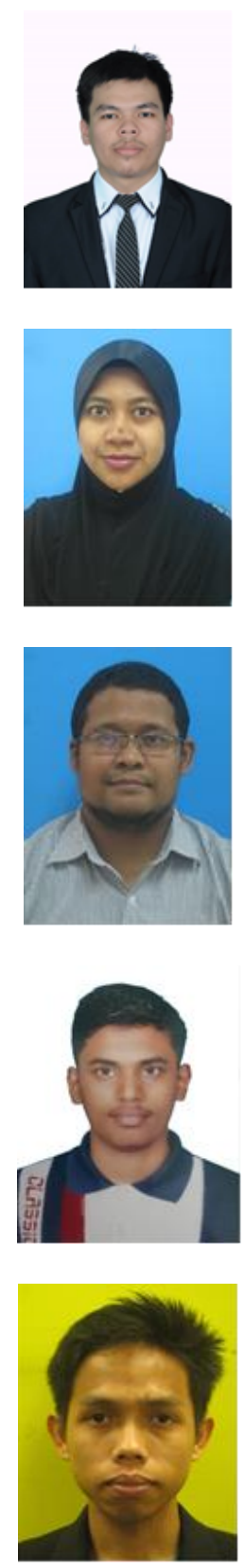

Mohammad Shafiq Che Soh has completed his Bachelor of Engineering (ElectricalElectronics) from Universiti Teknologi Malaysia, Malaysia in 2019.

Mastura Shafinaz Zainal Abidin is a Senior Lecturer in School of Electrical Engineering, Faculty of Engineering, Universiti Teknologi Malaysia, Malaysia. She obtained her Bachelor of Engineering (Electrical-Electronics) in 2008, Masters of Electrical Engineering-Electronics and Telecommunications in 2010; and Doctor of Philosophy in Electrical Engineering in 2014 from Universiti Teknologi Malaysia. Her research interest is semiconductor, electronic device, sensor fabrication and characterization.

Shaharin Fadzli Abd Rahman is a Senior Lecturer in School of Electrical Engineering, Faculty of Engineering, Universiti Teknologi Malaysia, Malaysia. He completed his Bachelor of Engineering degree and Master of Engineering from Hokkaido University, Japan in 2007 and 2009, respectively. In 2013, he obtained Doctor of Philosophy in Electrical Engineering from Universiti Teknologi Malaysia, Malaysia. His research interest is semiconductor and graphenebased electronic device and sensor fabrication and characterization.

Shuthish Elangkovan has completed his Bachelor of Engineering (Electrical-Electronics) from Universiti Teknologi Malaysia, Malaysia in 2019.

Ahmad Bukhairi Md Rashid is currently doing his Master of Philosphy degree in Electrical Engineering at School of Electrical Engineering, Universiti Teknologi Malaysia, Malaysia. He has completed his Bachelor of Engineering (Electrical-Electronics) from Universiti Teknologi Malaysia, Malaysia in 2017. 